\title{
Walking Accessibility to Parks: Considering Number of Parks, Surface Area and Type of Activities
}

\author{
Karl El-Murr ${ }^{1}$, Arianne Robillard ${ }^{1}$, Owen Waygood ${ }^{1}$, Geneviève Boisjoly ${ }^{1}$ (1) \\ ${ }^{1}$ Civil, geological and mining engineering, Polytechnique Montréal \\ Keywords: accessibility indicators, walking, open data, spatial analysis \\ https://doi.org/10.32866/001c.27479
}

Findings

\begin{abstract}
Parks and green spaces are desirable destinations for diverse reasons including exercising, playing, relaxing, and socializing. In this paper, we demonstrate that simultaneously considering number of parks, surface area and type of activity provides an improved understanding of walking accessibility to parks in urban areas. Using open datasets and a configurable tool, we find that in Montreal, 95\% of the population have access to three or more parks, $83 \%$ can access 3 or more playgrounds, and $10 \%$ can access 3 or more open air activities within a $1 \mathrm{~km}$ walk. The accessible surface area varies considerably across the region. The tool reveals distinct patterns that better reflect the diversity of needs and uncovering specific inequalities, and can therefore contribute to improved decision-making.
\end{abstract}

\section{QUESTIONS}

Parks - including green spaces - play a significant role as free recreational spaces in urban areas (Tempesta 2015). Knowing that proximity to parks is associated with increased use and physical activity (Hartig et al. 2014), several efforts have been put on developing measures of accessibility to parks, with a focus on distances to the nearest park or on the number of parks accessible within a specific threshold. Yet, individuals visit parks for a variety of reasons (Sundevall and Jansson 2020) and this can influence the need for different equipment and/or more or less space. Understanding accessibility to parks in a disaggregated manner is thus essential.

Our research seeks to answer the following question: "How does accessibility to parks vary spatially across the City of Montreal considering the number of parks, surface area, and type of potential activities?" This research stems from the hypothesis that the accessibility outcomes will differ depending on the chosen variable (and activity type), which each reflect distinct needs and opportunities. A greater number of accessible parks may increase the likelihood of an appropriate park existing for the individual, while a greater surface area may be associated with a greater supply of green areas, perhaps better facilitating certain games and sports, relaxing, or socializing. The type of activities directly reflects the availability of specific opportunities.

\section{METHODS}

This study was conducted using land use and transport data available on the open data portal of the City of Montreal (Ville de Montreal 2021). First, three land use datasets were used: (i) residential lots, (ii) parks and green spaces (hereafter simply referred to as parks), and (iii) outdoor recreational, cultural and sport amenities. Numerous green spaces were removed from the parks 
dataset as they are not freely accessible (e.g., golf, private, institutional), for a total of 1,475 remaining parks. Activities located inside the remaining parks, obtained from the third dataset, are classified into five different categories by the City: sports, recreational (e.g., chess, climbing wall), open air (e.g., trail, wooded area), leisure (e.g., sliding area, ping pong table), and playgrounds, for a total of 3,078 activities. Second, a pedestrian network was generated from the public road dataset to only include pedestrian links, streets with sidewalks and residential streets without sidewalks. Finally, population data within the dissemination areas were retrieved from the 2016 census data (Statistics Canada 2016). The 1,704,689 residents of Montreal are thus counted in the 2,805 dissemination areas (DA).

Cumulative-opportunity accessibility measures were generated using a configurable tool currently under development (using the ArcGIS software). This tool first distributes the population from each DA inside the residential lots according to the surface area they occupy. It then determines the parks and activities that can be reached from each residential lot within a 1,000 m pedestrian network distance (roughly equivalent to a 15-minute walk), which represents the average distance walked by Montrealers (Lachapelle, Boisjoly, and Vermesch 2020). The tool is transferable to other contexts based on data availability, knowing that the user specified inputs are the following: population data within residential zones, origin and destination points, road network, and distance threshold.

To do so in this study, service areas were generated based on the pedestrian network for each park and activity. Since parks are represented by polygons, the service area of a single park comprises all service areas calculated from each access point along the perimeter (following Apparicio et al. (2010)'s approach). For the activities, represented by points, access is considered by assigning the point to the closest street (representing an access point).

Finally, the tool intersects the service areas with the centroids of the residential lots to identify all parks and activities that are within the 1,000 $\mathrm{m}$ threshold of each residential lot. From this output, the number of parks and activities accessible from each residential lot are counted, and the accessible surface area corresponds to the sum of the surface of the parks that are accessible.

\section{FINDINGS}

Figure 1 presents the number of parks accessible (as commonly measured in research and practice) from each residential lot in Montreal. Accessibility is quite uniform across the City, and approximately 95\% of the population of Montreal can reach 3 or more parks within 1,000 m of walking (Table 1 ).

Figure 2 illustrates the total surface area $\left(\mathrm{km}^{2}\right)$ that is accessible from each residential lot, while Table 2 distributes the population according to the total surface area of accessible green spaces. An equivalent area has been assigned to each surface area for ease of interpretation. This accessibility indicator shows 


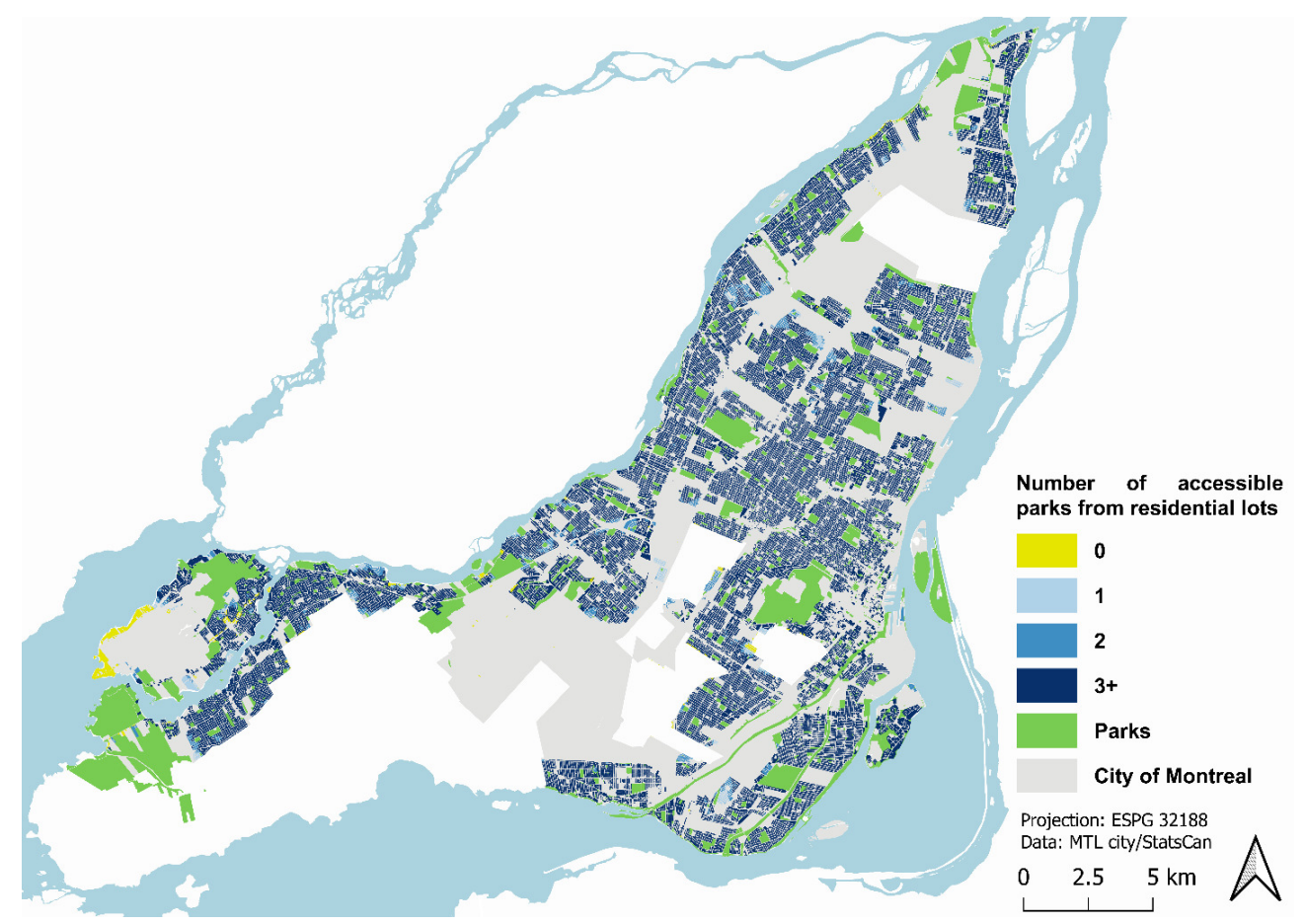

Figure 1. Number of accessible parks from residential lots in Montreal

Table 1. Distribution of the population based on the number of parks accessible.

\begin{tabular}{|c|c|c|c|c|}
\hline & $\begin{array}{l}\text { Population with } \\
\text { access to } 0 \text { or more } \\
\text { opportunities }\end{array}$ & $\begin{array}{l}\text { Population with } \\
\text { access to } 1 \text { or more } \\
\text { opportunities }\end{array}$ & $\begin{array}{l}\text { Population with } \\
\text { access to } 2 \text { or more } \\
\text { opportunities }\end{array}$ & $\begin{array}{l}\text { Population with } \\
\text { access to } 3 \text { or more } \\
\text { opportunities }\end{array}$ \\
\hline Parks & $100 \%$ & $99.6 \%$ & $98.4 \%$ & $95.0 \%$ \\
\hline
\end{tabular}

that even if $95 \%$ of the population has access to 3 or more parks, access with respect to surface area varies considerably. Most of the population has access to at least the equivalent area of one urban park (76\%), whereas only 18.4 and $12.8 \%$ of the population have access to at least more than $0.5 \mathrm{~km}^{2}$ and $1 \mathrm{~km}^{2}$ respectively. This latter is highly concentrated around the few largest parks of the city. This spatial pattern (Figure 2) highlights spatial inequalities that are not captured by the number of accessible parks.

Table 3 presents the number of activities (located within parks) accessible from residential lots, by type of activity. Most of the population $(82.9 \%)$ has access to $3+$ playgrounds and $3+$ recreational activities. Conversely, only $10 \%$ of the population has access to $3+$ open air activities, and nearly half of the population has no access to open air activities.

To illustrate these discrepancies, $\underline{\text { Figure } 3}$ compares accessibility to playgrounds with accessibility to open air activities. Stark contrasts are visible. On the one hand, accessibility to playgrounds, which mainly caters to children, is consistently high across the City of Montreal, except for specific areas that would require attention. It should be noted that providing children with 


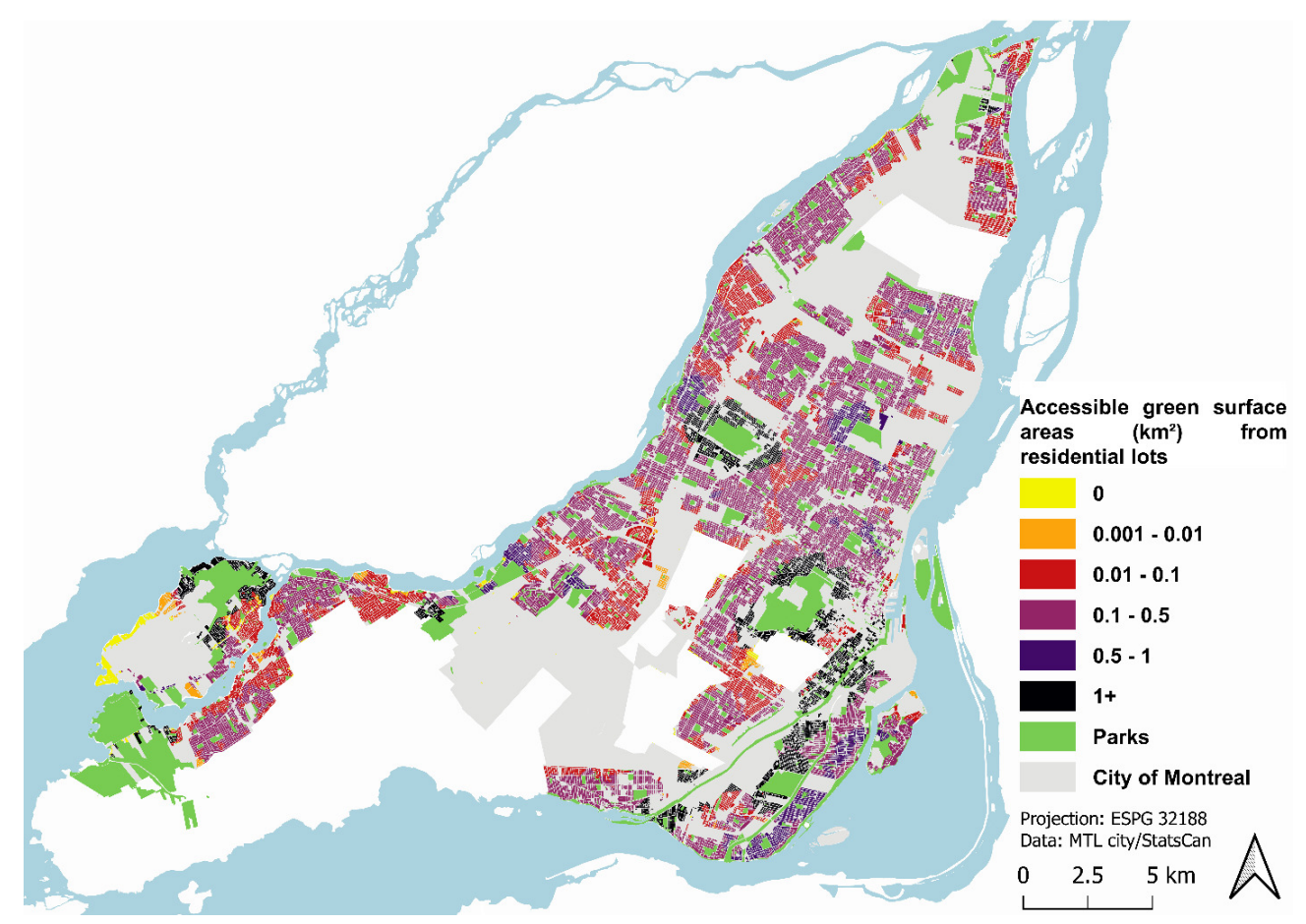

Figure 2. Accessible green surface areas $(\mathrm{km} 2)$ from residential lots in Montreal

Table 2. Distribution of the population based on the surface areas accessible

\begin{tabular}{ccc}
\hline Surface area $\left(\mathrm{km}^{2}\right)$ & Equivalent surface area & Population with access to at least the equivalent surface area \\
\hline 0 & - & $100 \%$ \\
\hline $0.001+$ & Football or Swimming pool & $99.6 \%$ \\
\hline $0.01+$ & Neighborhood Park & $98.6 \%$ \\
\hline $0.1+$ & Urban Park & $76 \%$ \\
\hline $0.5+$ & "Hyde Park", London & $18.4 \%$ \\
\hline $1+$ & "Central Park", New York & $12.8 \%$ \\
\hline
\end{tabular}

Table 3. Distribution of the population based on the number of activities accessible by type

\begin{tabular}{ccccc}
\hline $\begin{array}{c}\text { Type of } \\
\text { activity }\end{array}$ & $\begin{array}{c}\text { Population with access } \\
\text { to 0 activity }\end{array}$ & $\begin{array}{c}\text { Population with access } \\
\text { to 1 activity }\end{array}$ & $\begin{array}{c}\text { Population with access } \\
\text { to 2 activities }\end{array}$ & $\begin{array}{c}\text { Population with access } \\
\text { to 3+ activities }\end{array}$ \\
\hline Playgrounds & $2.6 \%$ & $2.5 \%$ & $12.1 \%$ & $82.9 \%$ \\
\hline Open Air & $46.2 \%$ & $27.6 \%$ & $15.7 \%$ & $10.4 \%$ \\
\hline Sports & $15.4 \%$ & $16.8 \%$ & $15.2 \%$ & $52.6 \%$ \\
\hline Recreational & $9.5 \%$ & $6.3 \%$ & $7.4 \%$ & $76.9 \%$ \\
\hline Leisure & $16.1 \%$ & $15.9 \%$ & $16.9 \%$ & $51.0 \%$ \\
\hline
\end{tabular}




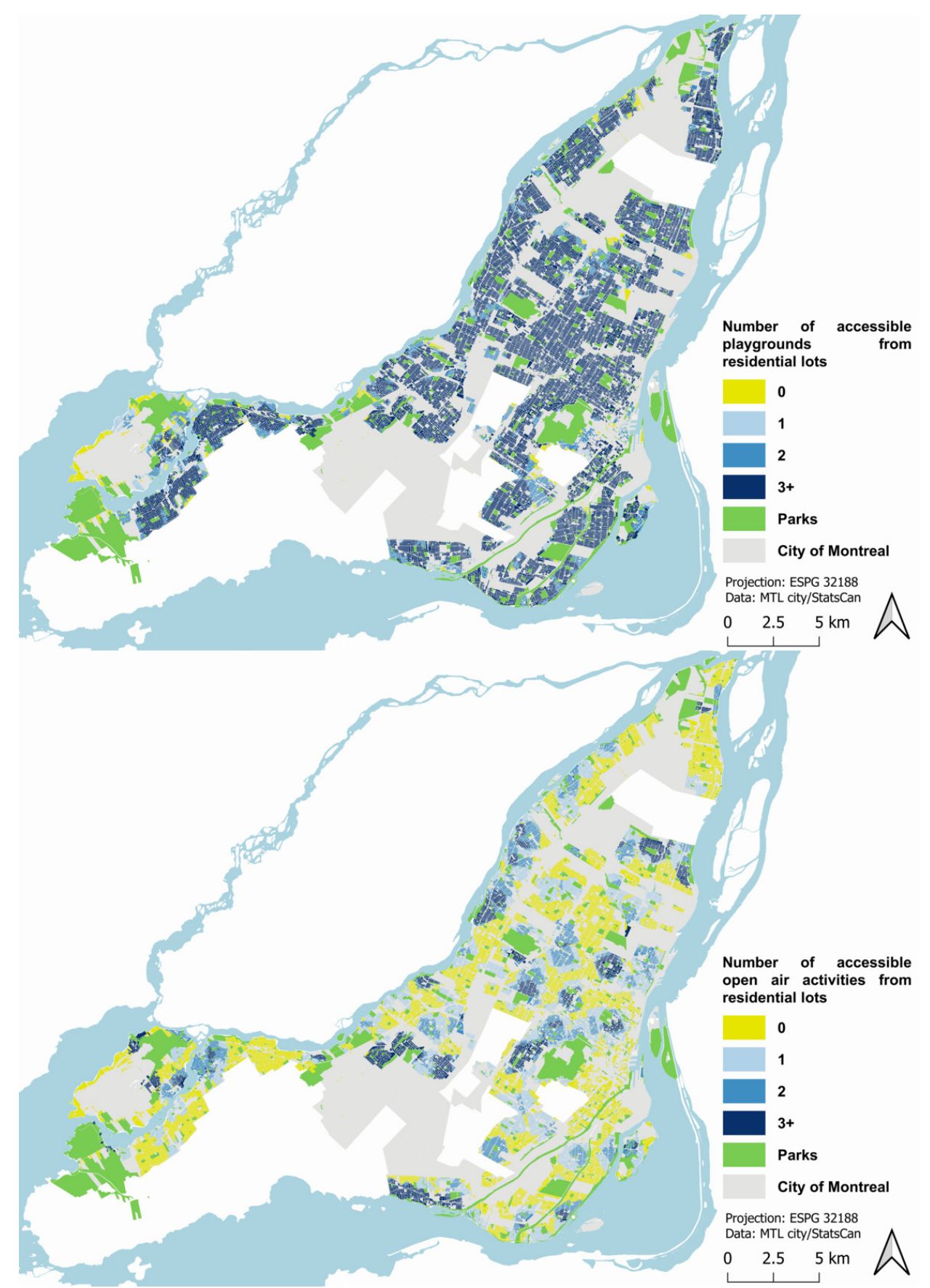

Figure 3. Number of accessible playgrounds vs. number of accessible open air activities from residential lots in Montreal

walking accessibility to key destinations such as playgrounds is especially relevant, as they do not typically have the same levels of mobility as adults do with restrictions placed on their travel spheres (Waygood et al. 2017). On the other hand, access to open air activities varies significantly, with large areas without access to open air activities being scattered across the territory.

The results show clearly distinct patterns with respect to number and type of activities, surface area and number of parks. The development of a tool that simultaneously computes these distinct indicators with the same data allows for a more nuanced understanding of accessibility to parks and green spaces in 
a region. While this study focuses on Montreal, the approach is transferable to other contexts and can be used to assess how different measures relate to parks' use and to improve decision-making.

\section{ACKNOWLEDGMENTS}

The authors would like to acknowledge Jalon Montreal for collaborating in the development of the configurable accessibility tool based on open datasets in the City of Montréal.

Submitted: July 01, 2021 AEDT, Accepted: August 16, 2021 AEDT

This is an open-access article distributed under the terms of the Creative Commons Attribution 4.0 International License (CCBY-SA-4.0). View this license's legal deed at https://creativecommons.org/ licenses/by-sa/4.0 and legal code at https://creativecommons.org/licenses/by-sa/4.0/legalcode for more information. 


\section{REFERENCES}

Apparicio, Philippe, Marie-Soleil Cloutier, Anne-Marie Séguin, and Josefina Ades. 2010.

"Accessibilité spatiale aux parcs urbains pour les enfants et injustice environnementale. Exploration du cas montréalais." Revue internationale de géomatique 20 (3): 363-89. https://doi.org/10.3166/ rig.20.363-389.

Hartig, Terry, Richard Mitchell, Sjerp De Vries, and Howard Frumkin. 2014. "Nature and Health." Annual Review of Public Health 35: 207-28. https://doi.org/10.1146/annurevpublhealth-032013-182443.

Lachapelle, Ugo, Geneviève Boisjoly, and Pauline Vermesch. 2020. "Réalisation d'un portrait des besoins et des habitudes de déplacements des personnes vivant en situation de précarité dans la région de Montréal."

Statistics Canada. 2016. “Census Profile, 2016 Census.” https://www12.statcan.gc.ca/censusrecensement/2016/dp-pd/prof/index.cfm?Lang=E.

Sundevall, Elin P, and Märit Jansson. 2020. "Inclusive Parks across Ages: Multifunction and Urban Open Space Management for Children, Adolescents, and the Elderly." International Journal of Environmental Research Public Health 17 (24): 9357. https://doi.org/10.3390/ijerph17249357.

Tempesta, Tiziano. 2015. "Benefits and Costs of Urban Parks: A Review.” Aestimum, 127-43. https://doi.org/10.13128/Aestimum-17943.

Ville de Montreal. 2021. https://donnees.montreal.ca/.

Waygood, Edward Owen Douglas, Margareta Friman, Lars E Olsson, and Ayako Taniguchi. 2017. “Transport and Child Well-Being: An Integrative Review.” Travel Behaviour Society 9: 32-49. https://doi.org/10.1016/j.tbs.2017.04.005. 